\title{
Improvement of Vision after Resection of Pituitary Tumor
}

\author{
Hari Poudel, ${ }^{1}$ BikeshKhambu, ${ }^{1}$ Rajendra Shrestha, ${ }^{1}$ Nilam Khadka, ${ }^{1}$ Rajeev Jha, ${ }^{1}$ Prakash Bista ${ }^{1}$
}

${ }^{1}$ Department of Neurosurgery, National Academy of Medical Sciences (NAMS), Bir Hospital, Kathmandu, Nepal.

\begin{abstract}
Background: Pituitary adenomas are the most common type of pituitary disorder. Compression of anterior visual apparatus leads to impairment of vision. Visual impairment depends on individual relation between tumor and visual apparatus, duration of compression, timing of operative intervention amongst others. Surgical excision is treatment of choice for tumors causing impairment of vision. Predicting outcome after surgical decompression thus helps both patient and surgeon to make realistic expectations and avoid unnecessary complication from overzealous aggressiveness. Predictors of visual outcome are not well established. This study aims to identify factors that predict visual improvement after resection of pituitary tumor. Methods: A cross-sectional study was conducted to study factors associated with visual outcome and data was collected prospectively. Visual acuity was measured by using snellen's chart and categorized using WHO vision impairment scale for distant vision. Visual field was measured either by Humphrey or Goldmannperimetry. Visual evaluation was done before surgery and after 3 months of surgery. Data was analyzed using SPSS version 23. Results: Twenty-eight eyes of fourteen patients were evaluated. Mean age at presentation was 38 years. Mean duration of impairment of vision at presentation was 13 months. Nonfunctioning pituitary adenoma was the most common pathology. Mean size of tumor was $3.07 \mathrm{~cm}$. Visual acuity improvement was seen in $17(61 \%)$ and visual field improvement in $16(57 \%)$ of patients. Visual outcome was significantly affected by preoperative visual status and size of tumor. Extent of resection, duration of symptom were not associated with visual outcome. Conclusions: Excision of Pituitary tumor from sella provides enough decompression to anterior visual apparatus resulting in improvement of visual acuity and field of vision. Preoperative visual status and size of tumor can predict postoperative visual outcome.
\end{abstract}

Keywords: pituitary adenoma, predictors, trans-sphenoidal resection, visual outcome, visual improvement.

\section{INTRODUCTION}

Pituitary adenomas are the most common type of pituitary disorder. ${ }^{1}$ They are benign neoplasms that account for $10 \%$ to $15 \%$ of all intracranial masses. Due to strategic location, visual impairment is common in pituitary tumors. Transsphenoidal surgery remains the treatment of choice, resulting in improvement of visual field defects in $75-100 \%$ of visually impaired patients with pituitary adenoma. ${ }^{2,3,4}$ The sella turcica forces an expanding adenoma superiorly, leading to compression of the optic nerve and headaches from mass effect. When the tumor enlarges, it compresses the optic chiasm superiorly, primarily causing visual field deficits, most often bitemporal hemianopia. A relationship exists between severity of visual impairment and tumor size. ${ }^{5}$ Surgical management of pituitary adenoma is aimed at resecting adenoma, attaining hormonal remission and cure from symptoms caused by mass effect of lesion. Contrary to global scenario, patients present to our center very late with large lesions. Visual changes are expected more often to continue to disable our patients. So, we planned a prospective study to evaluate visual changes after pituitary adenoma excision.

\section{METHODS}

A cross-sectional study was done at National Neurosurgical Referral center, NAMS-Bir Hospital. All patients who had pituitary adenoma with visual impairment and underwent resection of tumor with curative intent were included prospectively. Informed consent was taken from patients. Preoperative visual acuity was assessed by snellen's chart and categorized as WHO classification of visual impairment for distant vision. Patients were stratified into mild presenting visual acuity worse than 6/12(I), moderate - presenting visual acuity worse than 6/18(II), severe - presenting visual acuity worse than 6/60(III) and blindness - presenting visual acuity worse than $3 / 60(\mathrm{IV})$. Visual Field was assessed using Humphrey or Goldmann's perimetry. Visual field defects were scored semiquantitatively and classified as mild, moderate or severe. Visual field defect was classified as mild, if there was peripheral defect in only one quadrant.

Correspondence: Dr. Hari Poudel, Department of Neurosurgery, National Academy of Medical Sciences (NAMS), Bir Hospital, Kathmandu. Email: drharipoudel@gmail.com. Phone: +977-9856066321. Article received: 2019-05-25. Article accepted: 2019-07-28. 
Defect were classified as moderate if the upper quadrant were affected, whereas in combined upper and lower quadrant field defect was classified as severe. Visual assessment was repeated three months after surgery. Recordings were done for both eyes separately. Study was done for a period of one year from March 2018 to April 2019. Patients' demographic data, visual assessment, size of tumor in MRI, Completeness of surgical resection were documented. Study proposal was approved and supervised by Institution Research Board of NAMS. Sample size of twenty eight eyes was taken. Statistical analyses was performed using the SPSS 23.0 software (SPSS, Inc., Chicago, IL, USA). Descriptive statistics of ratio scaled variables were expressed as mean \pm standard deviation (SD). Relationships between visual improvement and other ordinal data was studied by spearman rho test. Binomial variables will be tested using Chi-square. Visual acuity and field before and after surgery was evaluated using paired t-test. Values of $P<0.05$ will be considered statistically significant.

\section{RESULTS}

Fourteen patients who had visual impairment and underwent surgery for excision of pituitary tumor were analysed. Out of fourteen patients, six (43\%) were female. Mean age at presentation was $38.86 \pm 12.68$ (16-66) years. Headache was most common nonvisual symptom followed by amenorrhea and acromegaly. Mean duration of visual alteration was $13.71 \pm 10.83$ (1-36) months (Table 1).

Fundoscopy revealed temporal paleness in ten

\begin{tabular}{|c|c|c|}
\hline \multicolumn{3}{|c|}{$\begin{array}{l}\text { Table 1. Baseline characteristics of sample } \\
\text { Aoe }\end{array}$} \\
\hline \multicolumn{2}{|c|}{ Sex(Male: Female) } & $3: 4$ \\
\hline \multirow[t]{3}{*}{$\begin{array}{l}\text { Tumor } \\
\text { Type }\end{array}$} & $\begin{array}{l}\text { Non-functioning } \\
\text { pituitary adenoma }\end{array}$ & $50 \%$ \\
\hline & Prolactinomas & $29 \%$ \\
\hline & Acromegaly & $21 \%$ \\
\hline \multirow{2}{*}{\multicolumn{2}{|c|}{$\begin{array}{l}\text { Tumor Size } \\
\text { Duration of Symptom }\end{array}$}} & $3.07 \pm 1.1(1.5-5.0) \mathrm{cm}$. \\
\hline & & $\begin{array}{l}13.71 \pm 10.83(1-36) \\
\text { month }\end{array}$ \\
\hline
\end{tabular}

$(35 \%)$, papilledema in six $(21 \%)$, optic atrophy in five $(18 \%)$ and normal in seven $(25 \%)$ eyes (Figure 1). Nonfunctioning pituitary adenoma $(50 \%)$ was most common tumor followed by prolactinomas (29\%) and acromegaly (21\%). Average size of tumor was $3.07 \pm 1.1(1.5-5.0) \mathrm{cms}$. Thirteen (92\%) patients had endonasal transsphenoidal approach while three $(22 \%)$ patients underwent transcranial resection. Two had a second stage transcranial surgery. Tumor resection was complete in eleven $(78.57 \%)$ patients. Visual acuity was stratified as per WHO classification of visual impairment. Visual acuity at presentation and after 3 months is depicted in (Figure 1).

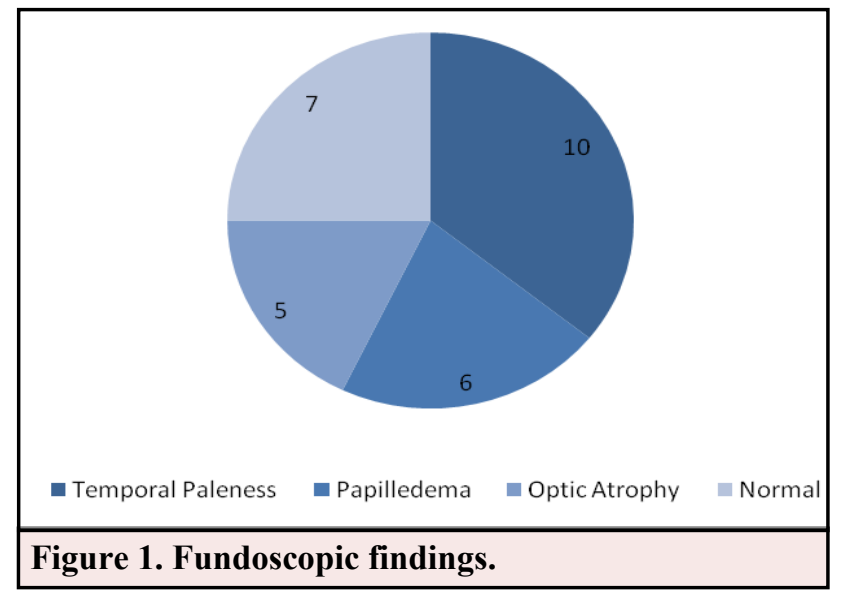

Four eyes had normal visual acuity, six grade I, nine Grade II visual impairment. Visual acuity improvement was marked in Group III. Visual acuity improvement was seen in seventeen $(60 \%)$ eyes. The mean of improvement of visual acuity in preoperative and postoperative study was statistically significant ( $\mathrm{p}$-value $=0.047$, CI $95 \%$ $=0.039-0.639$ ). Visual field was semi quantitatively stratified into mild, moderate and severe deficit. Visual field in preoperative and postoperative subjects was as depicted in (Figure 2).

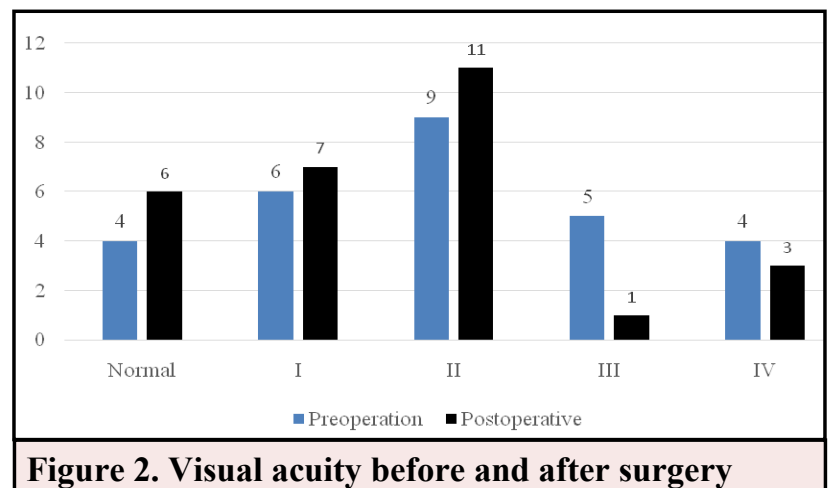

Figure 2. Visual acuity before and after surgery

Sixteen $(57 \%)$ eyes had improvement in visual field (Figure 3).

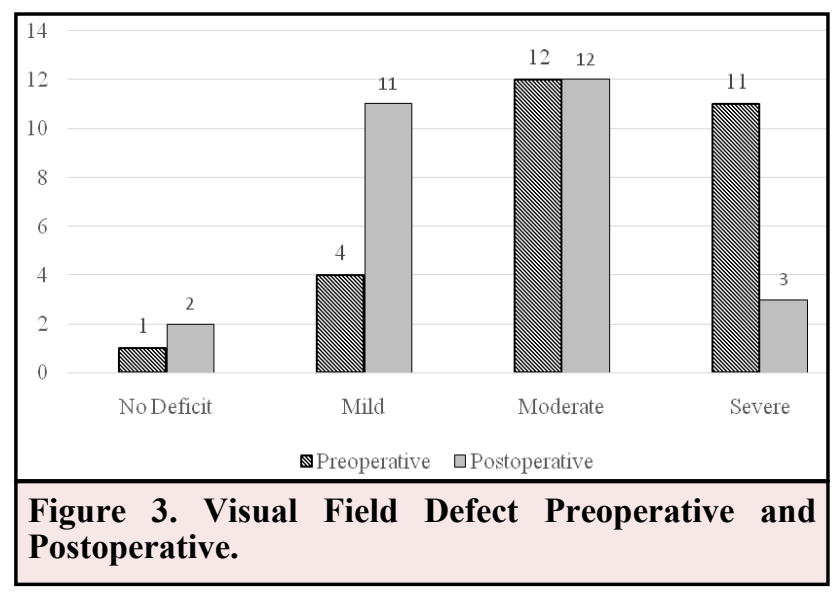


Improvement of visual field was statistically associated with size of tumor at presentation ( $\mathrm{p}$ value $=0.028)$. However association with duration of symptom $(p$-value $=0.98)$, presence of optic atrophy $(\mathrm{p}$-value $=0.112)$, improvement in visual acuity $(\mathrm{p}$ value $=0.83)$, completeness of excision ( $p$ value $=0.25)$, size of tumor $(p-v a l u e=0.12)$ was not statistically significant. Imaging and perimetry of a case who had improvement in both visual field and acuity following surgery is shown in (Figure 4).

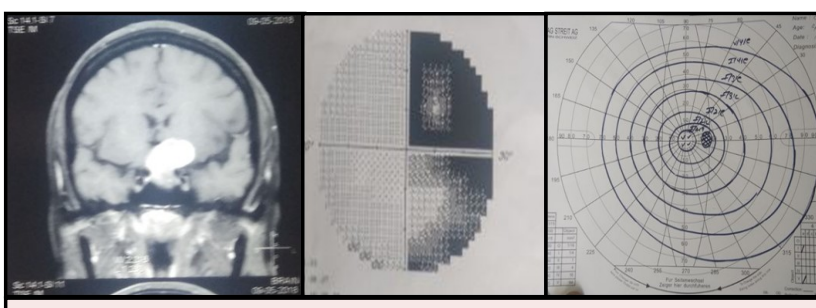

Figure 4. Pre-operative MRI (left) showing sellar mass with suprasellar extension with compression of visual apparatus more on left side, preoperative perimetry (middle) showing temporal loss in upper and lower quadrant, Postoperative perimetry (right) showing good recovery.

\section{DISCUSSION}

Visual impairment is a common presentation of pituitary tumor. Prediction of visual outcome after surgery is a key concern for management of pituitary tumor. Various studies ${ }^{6-11}$ have heterogeneous results on visual outcome following surgery. Majority of Studies were retrospective. Surgical excision is the treatment of choice in pituitary adenoma with significant mass effect. Pituitary adenoma is disease of young adults. Mean age of patients in our study was $38.86 \mathrm{yrs}$. This is lower compared to similar studies. ${ }^{4,6,12}$ Like other studies, ${ }^{12}$ majority of patients in our series were female. Duration of symptom before presentation was longer (13 months) than previous studies. ${ }^{6,12,13}$ Mean size of tumor was larger in $(3.07 \mathrm{cms})$ in our study. Nonfunctioning tumors were most common. Our study showed less recovery of visual field in patients with bigger tumors. This is in coherence with other studies. ${ }^{6,14}$ Larger tumors need to be prioritized for surgery. Optic atrophy was present in $18 \%$ in our series which was comparable to other studies $(7-30 \%)^{6,7,13}$ These patients had poor improvement of both visual acuity and field of vision. Mean duration of visual loss in our patients was 13.71 months. This is higher than previous studies. ${ }^{7,12}$ Longer duration tumors tend to have bad visual outcome. ${ }^{6,13,15}$ Complete excision at times is not safe due to potential risk to vital vascular structures, extension to extra sellar space. Choice of route of approach to sella could be trans-sphenoidal or cranial. Gross resection was achieved in 11 $(78 \%)$ patients in our series. However there was no significant association between completeness of resection and improvement of visual field defect. This is similar to prior studies by Gnanalingham ${ }^{6}$ and Musluman. ${ }^{7}$ Two patients needed two stage surgery from different routes. We used WHO grading of visual impairment of distant vision to categorize Visual acuity. Other studies use snellen's chart lines to quantify visual acuity. We have used semi quantitative measures of classification of visual field defect. Our study showed preoperative Visual Acuity, Visual field, improvement of Visual acuity and size of tumor to be significantly associated with visual field improvement. Improvement of visual acuity at three months was $51 \%$ in our series.

\section{CONCLUSIONS}

Excision of Pituitary tumor from sella provides enough decompression to anterior visual apparatus resulting in improvement of visual acuity and field of vision. Preoperative visual status and size of tumor can predict postoperative visual outcome.

\section{REFERENCES}

1. Famini P, Maya MM, Melmed S. Pituitary magnetic resonance imaging for sellar and parasellar masses: ten-year experience in 2598 patients. J ClinEndocrinolMetab. 2011;96 (6):1633-1641.

2. Fernandez A, Karavitaki N, Wass JA. Prevalence of pituitary adenomas: a community -based, cross-sectional study in Banbury (Oxfordshire, UK). ClinEndocrinol (Oxf). 2010;72(3):377-382.

3. Daly AF, Rixhon M, Adam C, Dempegioti A, Tichomirowa MA, Beckers A. High prevalence of pituitary adenomas: a cross-sectional study in the prov-ince of Liege, Belgium. J ClinEndocrinolMetab. 2006;91(12):4769-4775.

4. Dekkers OM, de Keizer RJ, Roelfsema F et al. Progressive improvement of impaired visual acuity during the first year after transsphenoidal

surgery for non-functioning pituitary macroadenoma. Pituitary 2007; 10 (01) 61-65.

5. Thomas R, Shenoy K, Seshadri MS, Muliyil J, Rao A, Paul P. Visual field defects in nonfunctioning pituitary adenomas. Indian $\mathrm{J}$ Ophthalmol. 2002;50:127-130.

6. Gnanalingham KK, Bhattacharjee S, Pennington $\mathrm{R}$, Ng J, Mendoza N. The time course of visual field recovery following transphenoidal surgery for pituitary adenomas: predictive factors for a good outcome. J NeurolNeurosurg Psychiatry. 2005;76(3):415-9.

7. Musluman AM, Cansever T, Yilmaz A, Kanat A, Oba E, Cavusoglu H, et al. Surgical results of large and giant pituitary adenomas with special consideration of ophthalmologic outcomes. World Neurosurg. 2011;76(1-2):141 -8 .

8. Svien HJ, Love JG, Kennedy WC, Colby MY, 
Jr, Kearns TP. Status of vision following surgical treatment for pituitary chromophobe adenoma. J Neurosurg. 1965;22:47-52.

9. Marazuela M., Astigarraga B., Vicente A., et al. Recovery of visual and endocrine function following transsphenoidal surgery of large nonfunctioning pituitary adenomas. Journal of Endocrinological Investigation. 1994;17(9):703 $-707$.

10. Ihsan Anik, YoncaAnik, BurakCabuk et al. Visual Outcome of an Endoscopic EndonasalTranssphenoidal Approach in Pituitary Macroadenomas: Quantitative Assessment with Diffusion Tensor Imaging Early and Long-Term Results.World Neurosurgery.2018;112

11. Dutta Pinaki, Gyurmey Tenzin, Bansal Reema et al. Visual outcome in 2000 eyes following microscopic transsphenoidal surgery for pituitary adenomas: Protracted blindness should not be a deterrent. Neurol India.2016;64(6): $1247-1253$
12. Okamoto Y, Okamoto F, Yamada S, Honda M, Hiraoka T, Oshika T. Vision-related quality of life after transsphenoidal surgery for pituitary adenoma. Invest Ophthalmol Vis Sci 2010;51 (7):3405-3410

13. Amin MR, Nath HD, Hossain MA, Barua KK. Early post-operative visual outcome in patient with pituitary adenoma. Banglad $\mathrm{J}$ Neurosci 2012;28(2):108-115.

14. Monteiro MLR, Zambon BK, Cunha LP. Predictive factors for the development of visual loss in patients with pituitary macroadenomas and for visual recovery after optic pathway decompression. Can J Ophthalmol 2010;45 (4):404-408.

15. Tokumaru AM, Sakata I, Terada H, Kosuda S, Nawashiro $H$, Yoshii M. Optic nerve hyperintensity on T2-weighted images among patients with pituitary macroadenoma: correlation with visual impairment. AJNR Am Neuroradiol 2006;27(2):250-254.

Citation: Poudel H, Khambu B, Shrestha R, Khadka N, Jha R, Bista. Improvement of Vision after Resection of Pituitary Tumor. JCMS Nepal. 2019; 15(3):167-70. 